\title{
Analisis Kesesuaian Konsep Struktur Atom Pada Buku Kimia Kelas X SMA/MA Terhadap Silabus Kurikulum 2013 Edisi Revisi Dan Penyusunan Makro Wacana
}

\author{
Desy Natalia*, Abdul Hadjranul Fatah, Mulawi \\ Program Studi Pendidikan Kimia, UniversitasPalangka Raya, Indonesia \\ *Email: desydesnata@gmail.com
}

\begin{abstract}
Abstrak
Tujuan penelitian adalah untuk: (1) Mendeskripsikan kesesuaian konsep struktur atom terhadap silabus Kurikulum 2013 edisi revisi, (2) Mendeskripsikan struktur makro wacana dalam materi ajar kimia SMA/MA kelas X hasil analisis pada konsep struktur atom, (3) Mendeskripsikan proposisi apa saja yang berpotensi kesalahan konsep yang terdapat pada narasi materi struktur atom SMA/MA kelas X SMA/MA pada buku A dan buku B.

Penelitian ini merupakan jenis penelitian deskriptif dengan pendekatan kualitatif. Objek penelitian ini adalah (1) buku teks Kimia SMA/MA kelas X Penulis Unggul Sudarmo yang diterbitkan oleh Penerbir Erlangga tahun 2016 (Buku A), (2) buku teks Kimia SMA/MA kelas X Penulis A. Haris Watoni Dkk yang diterbitkan oleh Penerbit Yrama Widya tahun 2016 (Buku B).

Hasil penelitian menunjukan Jumlah label konsep gabungan dari kedua buku adalah 29 label konsep. Pada buku A mempunyai 26 label konsep dan buku B mempunyai 25 label konsep yang sesuai dengan silabus Kurikulum 2013 edisi revisi. Proposisi kesalahan konsep pada buku teks A yaitu: pemahan kata dan gambar percobaan Rutherford tampa dijelaskan. Proposisi kesalahan konsep pada buku teks B yaitu kata yang sulit dipahami dan jumlah subkulit yang tidak tepat.
\end{abstract}

Kata Kunci: Analisis konsep, Struktur Atom, Kurikulum 2013, Wacana, Proposisi 
Desy Natalia (175-183)

\section{Pendahuluan}

Kesulitan siswa dalam memahami suatu konsep akan menghambat siswa dalam memahami konsep berikutya. Kesulitan tersebut disebabkan oleh karakterisitik kimia yang mempunyai konsep yang saling berkaitan antara satu sama lainya (Kaya \& Geban, 2012). Hal ini berarti ketidakmampuan siswa dalam memahami suatu konsep akan berakibat pada ketidak pahaman terhadap konsep berikutnya (Darmana, dkk 2013).

Hasil penelitian ini diharapkan dapat memberikan informasi mengenai analisis materi ajar Kimia SMA/MA agar mampu memilih atau menggunakan materi ajar dengan baik dan mudah dipahami. Memberikan pengetahuan kepada guru tentang kriteria materi ajar kimia yang baik untuk digunakan siswa. Membantu guru dalam memilih materi ajar Kimia yang akan digunakan siswa untuk belajar mandiri. Menjadi salah satu pertimbangan bagi penerbit dan editor dalam menyusun materi ajar.

Kesulitan siswa dalam memahami konsep struktur atom dapat diatasi dengan menciptakan Proses Belajar Mengajar (PBM) yang optimal. Ada tiga komponen utama yang perlu diperhatikan dalam mencapai tujuan tersebut yaitu guru, siswa, dan bahan ajar. Siswa mengkonstruksi pemahamannya sendiri ketika proses PBM, namun tidak ada jaminan bahwa siswa mampu mengkonstruksi pemahaman yang akurat (Ormrod, 2008). Maka dari itu, dibutuhkan media perantara yang mampu mengkonstruksi pemahaman siswa. Salah satu media perantaranya yaitu bahan ajar. Bahan ajar terdiri dari berbagai jenis salah satu diantaranya yaitu buku teks pelajaran. Buku teks pelajaran memainkan peran yang sangat penting dalam proses pembelajaran (Tesdelen \& Koseoglu, 2008). Buku 
teks pelajaran dapat membantu siswa mengkonstruksi pemahaman yang akurat sehingga siswa dengan mudah dapat memahami suatu materi.

Mendeskripsikan kesesuaian konsep struktur atom terhadap silabus Kurikulum 2013 edisi revisi. Mendeskripsikan struktur makro wacana dalam materi ajar kimia SMA/MA kelas X hasil analisis pada konsep struktur atom. Mendeskripsikan proposisi apa saja yang berpotensi kesalahan konsep yang terdapat pada narasi materi struktur atom SMA/MA kelas X SMA/MA pada buku A dan buku B.

Menurut Arifin (2008), analisis wacana dilakukan dengan analisis teksdasar yang dibagi menjadi tiga tahap, yaitu: membuat teks dasar, menurunkan proposisi makro dan mikro, dan menurunkan struktur makro. Tahapan analisis wacana dilakukan adalah sebagai berikut: Pembentukan teks dasar, Menurunkan proposisi mikro dan makro, Menurunkan struktur makro.

Konsep menurut Gagne (1977), konsep merupakan suatu abstraksi yang melibatkan hubungan antar konsep (relational concepts) dan dapat dibentuk oleh individu dengan mengelompokkan objek, merespon objek tersebut dan kemudian memberinya label (concept by definition). Konsepsi merupakan kemampuan memahami konsep, baik yang diperoleh melalui interaksi dengan lingkungan maupun konsep yang diperoleh dari pendidikan normal (Suparno, 2005). Pengertiankonsepsi adalah sebuah interpretasi dan tafsiran perorangan pada suatu konsep ilmu yang diperoleh melalui interaksi dengan lingkungan dan melalui pendidikan formal.

Buku teks adalah buku pelajaran dalam bidang studi tertentuyang merupakan buku standar yang disusun oleh para pakar dan bidang itu 
untukmaksud-maksud dan tujuan instruksional, yang dilengkapi dengan saranasarana pengajaran yang serasi dan mudah dipahami oleh para pemakainya di sekolah-sekolah dan perguruan tinggi sehingga dapat menunjang suatu program pengajaran. Peraturan Menteri Pendidikan Nasional Nomor 11 Tahun 2005 menjelaskan bahwa buku teks adalah buku acuan wajib untuk digunakan di sekolah yang memuat materi pembelajaran dalam rangka peningkatan keimanan dan ketakwaan, budi pekerti dan kepribadian, kemampuan penguasaan ilmu pengetahuan dan teknologi, kepekaan dan kemampuan estetis, serta potensi fisik dan kesehatan yang disusun berdasarkan standar nasional pendidikan. Menurut taksanomi Bloom, semua konsep memiliki nama atau label dan banyak atau sedikitnya sesuai dengan definisi. Konsep juga memiliki atribut yang dapat mendeskripsikan dan membantu mendefinisikan agar menjadi label konsep. Label konsep diperoleh dari buku teks yang digunakan. Faktor yang mempengaruhi terbentuknya label konsep adalah jenis pengetahuan. Atom merupakan bagian terkecil suatu materi yang tidak dapat dibagi lagi. Akan tetapi, atom mempunyai partikel-partikel penyusun. Gambaran susunan partikel-partikel dasar dalam atom disebut model atom.

\section{Metodelogi Penelitian}

Metode pada penelitian ini yaitu menggunakan metode deskriptif. Instrumen penelitian digunakan yaitu tabel Analisis konsep materi tabel Analisis struktur makro wacana, dan tabel analisis proposisi kesalahan konsep yang berpotensi. Teknik Analisis Data: 
Jurnal Ilmiah Kanderang Tingang

\begin{tabular}{|c|c|c|}
\hline $\begin{array}{l}\text { Data yang } \\
\text { dianalisis }\end{array}$ & Teknik Analisis Data & Instrumen \\
\hline Teks Dasar & $\begin{array}{l}\text { 1. Teks dasar yang diperoleh dimasukkan } \\
\text { kedalam tabel penurunan proposisi mikro dan } \\
\text { makro yang melalui proses penghapusan, } \\
\text { generalisasi, dan konstruksi. } \\
\text { 2. Proses penghapusan dilakukan untuk } \\
\text { menghilangkan kata-kata yang tidak diperlukan } \\
\text { sehingga akan menghasilkan proposisi mikro } \\
\text { dan makro. } \\
\text { 3. Proses generalisasi dapat diturunkan dari } \\
\text { proposisi tertentu sehingga dihasilkan proposisi } \\
\text { makro yang bersifat umum. } \\
\text { 4. Proses konstruksi dapat dihasilkan proposisi } \\
\text { baru, yaitu proposisi makro dibangun dari } \\
\text { beberapa proposisi mikro. } \\
\text { 5. Proposisi makro utama yang dihasilkan akan } \\
\text { dilakukan pemetaan kedalam struktur makro } \\
\text { wacana. }\end{array}$ & $\begin{array}{l}\text { Program } \\
\text { Microsoft Word }\end{array}$ \\
\hline $\begin{array}{l}\text { Teks yang } \\
\text { berpotensi } \\
\text { menimbulkan } \\
\text { kesalahan } \\
\text { konsep }\end{array}$ & $\begin{array}{l}\text { 1. Membandingkan proposisi pada teks dasar } \\
\text { dengan konsepsi peneliti dan konsep para ahli. } \\
\text { 2. Melakukan perbaikan teks dasar. }\end{array}$ & $\begin{array}{l}\text { Program } \\
\text { Microsoft Word }\end{array}$ \\
\hline
\end{tabular}

\section{Hasil Penelitian Dan Pembahasan}

Konsep struktur atom dibahas pada Bab II. Pada penelitian ini akan

dijelaskan hasil penelitian dan pembahasan mengenai relevansi antara teks asli dengan label konsep pada buku . Hasil identifikasi relevansi antara teks asli dengan label konsep pada buku.

\begin{tabular}{llll}
\hline No & \multicolumn{1}{c}{ Teks Hasil Penghalusan } & $\begin{array}{c}\text { Label } \\
\text { Konsep }\end{array}$ & $\begin{array}{c}\text { Jenis } \\
\text { Pengetahu } \\
\text { an }\end{array}$ \\
\hline 1 & $\begin{array}{l}\text { Atom merupakan bagian yang sangat kecil dari suatu } \\
\text { unsur yang masing memiliki sifat unsur tersebut }\end{array}$ & $\begin{array}{l}\text { Pengertian } \\
\text { Atom }\end{array}$ & Konseptual \\
\hline 2 & $\begin{array}{l}\text { Dalam penelitiannya, Rutherford menemukan suatu } \\
\text { kejanggalan, yaitu Perbandingan massa hidrogen } \\
\text { terhadap massa atom helium adalah 1: 4, di mana } \\
\text { hidrogen mempunyai 1 proton dan helium mempunyai } \\
\text { 2 proton. Seharusnya perbandingannya adalah 1:2. }\end{array}$ & Neutron & Faktual \\
\end{tabular}




\begin{tabular}{|c|c|c|c|}
\hline 3 & $\begin{array}{l}\text { Seperti yang sudah dijelaskan sebelumnya bahwa } \\
\text { konfigurasi elektron suatu atom adalah khas sehingga } \\
\text { terdapat beberapa atom yang konfigurasinya } \\
\text { menyimpang dari aturan-aturan umum tersebut, } \\
\text { misalnya: } \\
{ }_{24} \mathrm{Cr}:[\mathrm{Ar}] 4 \mathrm{~s}^{2} 3 \mathrm{~d}^{4} \text { kurang stabil, maka berubah menjadi } \\
\text { [Ar] } 4 \mathrm{~s}^{1} 3 \mathrm{~d}^{5} \\
{ }_{29} \mathrm{Cu}:[\mathrm{Ar}] 4 \mathrm{~s}^{2} 3 \mathrm{~d}^{9} \text { kurang stabil, maka berubah } \\
\text { menjadi [Ar] } 4 \mathrm{~s}^{1} 3 \mathrm{~d}^{10} \\
{ }_{46} \mathrm{Pd}:[\mathrm{Kr}] 5 \mathrm{~s}^{2} 4 \mathrm{~d}^{8} \text { kurang stabil, maka berubah menjadi } \\
{[\mathrm{kr}] 4 \mathrm{~d}^{10}} \\
{ }_{47} \mathrm{Ag}:[\mathrm{Kr}] 5 \mathrm{~s}^{2} 4 \mathrm{~d}^{9} \text { kurang stabil, maka berubah } \\
\text { menjadi }[\mathrm{Kr}] 5 \mathrm{~s}^{1} 4 \mathrm{~d}^{10}\end{array}$ & $\begin{array}{l}\text { Konfiguras } \\
\text { i Elektron }\end{array}$ & Prosedural \\
\hline 4 & $\begin{array}{l}\text { Terdapat pertanyaan yang belum dapat dijelaskan oleh } \\
\text { Ruhterford pada saat itu, yaitu bagaimanakah elektron } \\
\text { yang bermuatan negatif tidak tertarik ke dalam inti } \\
\text { atom yang bermuatan positif? Alasan yang diberikan } \\
\text { oleh Rutherford adalah gaya tarik inti terhapat elektron } \\
\text { dilawan oleh gaya setripetal akibat gerakan elektron } \\
\text { yang mengelilingi inti. Namun, jawaban ini pun belum } \\
\text { memuaskan karena bertentangan dengan teori Maxwell } \\
\text { yang mengatakan bila ada partikel bermuatan bergerak } \\
\text { maka akan memancarkan radiasi sehingga } \\
\text { kecepatannya makin turun. }\end{array}$ & $\begin{array}{l}\text { Model } \\
\text { Atom } \\
\text { Atom } \\
\text { Rutherford }\end{array}$ & $\begin{array}{l}\text { Metakogni } \\
\text { tif }\end{array}$ \\
\hline
\end{tabular}

Label konsep yang pertama yaitu pengertian atom memiliki jenis pengetahuan konseptual. Label konsep pengertian atom memiliki jenis pengetahuan konseptual dengan ciri-ciri jenis pengetahuan konseptualnya adalah ditampilkan pengetahuan tentang prinsip dan generalisasi berupa pengertian atom. Label konsep yang kedua yaitu percobaan tabung sinar katode memiliki jenis pengetahuan faktual dengan ciri-ciri ditampilkan informasi berupa dua jenis muatan listrik telah ditemukan oleh Benjamin Franklin (1760-1790). Ia menamakannya sebagai muatan positif (+) dan muatan negatif (-) karena kedua muatan ini dapat menetralkan satu sama lain. Ciri-ciri ini bersifat fakta maka dari itu termasuk dalam jenis pengetahuan faktual karna berdasaran sebuah fakta. Label konsep yang ketiga yaitu rumus menghitung massa elektron yaitu memiliki jenis pengetahuan prosedural. Label konsep rumus menghitung massa elektron memiliki jenis pengetahuan prosedural dengan ciri-ciri ditampilkan langkah- 
langkah atau urutan mengenai rumus menghitung massa elektron. Label konsep yang keempat teori atom Dalton memliki jenis pengetahuan metakognitif. Label konsep teori atom Dalton memiliki jenis pengetahuan meakognitif dengan ciri-ciri meliputi pengetahuan starategi, termasuk dalam kontekstual, dan kondisional. Jumlah label konsep untuk buku A yaitu 26 diantaranyateori atom Dalton, elektron, teori atom Thomson, inti atom, proton, teori atom Rutherford, neutron, nomor atom, nomor massa, isotop, isobar, isoton, teori atom Niels Bohr, elektron valensi, mekanika kuantum, gelombang elektromagnetik, percobaan spektrum atom hidrogen, mekanika gelombang, bilangan kuantum,orbital, subkulit, konfigurasi elektron, prinsif Aufbau, larangan Pauli, aturan Hund, dan konfigurasi ion. Jumlah label konsep untuk buku B yaitu 25diantaranyateori atom Dalton, inti atom, elektron, teori atom Thomson, proton, neutron, teori atom Rutherford, percobaan hamburan sinar alfa, percobaan spektrum atom hidrogen, nomor atom, nomor massa, lambang atom, isotop, isobar, isoton, isoelektronik, teori atom Bohr, teori atom mekanika gelombang, bilangan kuantum, orbital, konfigurasi elektron, aturan Hund, larangan Pauli, prinsif Aufbau, dan subkulit. Persamaan label konsep yang terdapat dalam buku teks A dan buku teks B yaitu berjumlah 22 yaitu teori atom Dalton, teori atom Thomson, teori atom Rutherford, teori atom Niels Bohr, teori atom mekanika gelombang, inti atom, proton, neutron, elektron, nomor atom, nomor massa, isoton, isobar, isotop, bilangan kuantum, konfigurasi elektron, orbital, percobaan spektrum atom hidrogen, aturan Hund, larangan Pauli, prinsip Aufbau, dan subkulit. Label konsep pada buku A lebih banyak dibandingkan pada buku B. Konsep teori atom (P-I) berada pada level 2 terdiri dari delapan makro bawahan, teori atom Dalton, teori atom Thomson, teori atom 
Rutherford, teori atom Niels Bohr, teori atom Mekanika Gelombang(beradapada level 3),terdiri dari dua makro bawahan, percobaan spektrum atom hidrogen, mekanika kuantum(berada pada level 4), dan pada terdiri dari satu makro bawahan yaitu gelombang elektromagnetik (berada pada level 5). Konsep yang didapat diperoleh dari proses penghalusan yang mengikuti aturan makro berdasarkan kriteria penghapusan, generalisasi, dan konstruksi. Label konsep teori atom terdiri dari label konsep teori atom Dalton, teori atom Thomson, teori atom Rutherford, teori atom Niels Bohr, teori atom Mekanika Gelombang, percobaan spektrum atom hidrogen, mekanika kuantum gelombang elektromagnetik. Konsep partikel subatom (P-II) berada pada level 2 terdiri dari delapan belas makro bawahan, inti atom dan elektron (berada pada level 3), proton, neutron, bilangan kuantum (berada pada level 4), nomor atom, isoton, nomor massa, orbital, subkulit, konfigurasi elektron, konfigurasi ion (berada pada level 5), isotop, isobar, prinsip Aufbau, larangan Pauli, aturan Hund, elektron valensi (berada pada level 6). Silabus kurikulum 2013 edisi revisi menjadi acuan sebgai rujukan untuk menyesuaikan label konsep pada buku teks A dan buku teks B dengan KD (Kompetensi Dasar) dan MP (Materi Pokok) pada silabus kurikulum 2013 edisi revisi agar materi (konsep) yang ada pada buku teks A dan buku teks B tidak hanya menjadi materi yang dituliskan tanpa ada acuannya. Proposisi yang berpotensi miskonsepsi yaitu terdapat pada kalimat bila atom-atom diurutkan berdasarkan jumlah protonnya, maka atom hidrogen akan mempunya nomor satu karena hanya mempunyai sebuah proton, helium nomor dua karena mempunyai dua buah proton, dan seterusnya memiliki makna yang sulituntuk dipahami oleh siswa sehingga menyebabkan siswa mengalami miskonsepsi. 


\section{Simpulan}

Hasil penelitian menunjukan Jumlah label konsep gabungan dari kedua buku adalah 29 label konsep. Pada buku A mempunyai 26 label konsep dan buku B mempunyai 25 label konsep yang sesuai dengan silabus Kurikulum 2013 edisi revisi. Proposisi kesalahan konsep pada buku teks A yaitu: pemahan kata dan gambar percobaan Rutherford tampa dijelaskan. Proposisi kesalahan konsep pada buku teks B yaitu kata yang sulit dipahami dan jumlah subkulit yang tidak tepat.

\section{Daftar Referensi}

Arifin. 2008. Pembuatan Hiperteks Akademik Pada Materi Kajian Kecepatan Reaksi dan Pemanfaatannya Sebagai media Pembelajaran Kimia di SMA. Palangka Raya: Penelitian, tidak diterbitkan. Universitas Palangka Raya.

Gagne,R. M dan Brigg, R. J. 1997. Condition of Learning. New York: Holt and Winston.

Kaya, E. E dan Geban, O. 2012. Facilitating Conceptual Change in Rate of Reaction Concepts Using Conceptual Change Oriented Instruction. Journal Education and Science 2012, Vol. 37, No 163

Ormrod, J.E. 2008. Psikologi Pendidikan Membantu Siswa Tumbuh dan Berkembang, Edisi Keenam. Jakarta: Erlangga.

Suparno, P. 2005. MiskonsepsidanPerubahanKonsepPendidikanFisika. Jakarta: PT Grasindo.

Tasdelen, U. \& Koseoglu, F. 2008. Learner-Friendly Text books: Chemistry Texts Based on a Constructivist View of Learning. Journal Asia Pacific Education Review. Vol. 9, No.2, 136-147. 